\section{Case Reports in Oncology}

\title{
Granular Cell Tumor of the Breast Coexisting with Ductal Carcinoma in situ: Case Report
}

\author{
Yuko Ueki ${ }^{a}$ Yoshiya Horimoto $^{a, b}$ Akihiko Shiraishic $^{c}$ Atsushi Arakawa $^{b}$ \\ Hyonmi Sai $^{a}$ Mitsue Saito $^{a}$ \\ aDepartment of Breast Oncology, Juntendo University School of Medicine, Tokyo, Japan; \\ bepartment of Human Pathology, Juntendo University School of Medicine, Tokyo, Japan; \\ 'Department of Radiology, Juntendo University School of Medicine, Tokyo, Japan
}

\author{
Keywords \\ Granular cell tumor - Breast cancer - Ductal carcinoma in situ · Coexisting · Surgical \\ procedure
}

\begin{abstract}
Granular cell tumor (GCT) is a benign tumor arising from Schwann cells. GCT of the breast is rare and while predominantly benign, it can be difficult to differentiate from breast cancer by imaging. While it is not generally associated with breast cancer, we here report a rare case of GCT coexisting with ductal carcinoma in situ (DCIS). A 38-year-old Japanese woman had microcalcification suggestive of malignancy in the right upper breast and a 6 -cm well-defined mass in the right lower breast. Ultrasonography showed that the lower mass was circular in shape with a clear border, and internal echo level was slightly uneven. Contrast-enhanced magnetic resonance imaging found that the inside was unevenly contrast-enhanced and showed fast/washout enhanced pattern. Hence, imaging could not exclude malignancy. Pathological diagnosis from biopsies taken from the upper calcification and lower mass was DCIS and GCT, respectively. Imaging showed no evidence of continuity between the two, but the patient elected for mastectomy. Final pathological diagnosis confirmed an S-100-positive and keratin-negative GCT for the lower lesion and no histological evidence of continuity. Although GCT is a rare disease, greater awareness of the disease and its imaging findings is needed to avoid overdiagnosis, particularly when it coexists with breast cancer.
\end{abstract}




\section{Introduction}

Granular cell tumor (GCT) is a benign tumor arising from Schwann cells of the peripheral nerve that can occur in various organs, most commonly the head, neck, and upper gastrointestinal tract. GCT of the breast is rare, occurring in 5\% of GCTs [1], and even rarer among all breast tumors. Only 1-2\% of GCTs are malignant [2], defined by Fanburg-Smith et al. [3] as having three or more of the following: presence of necrosis, appearance of spindle cells, large nuclear body, frequent mitosis, high rate of nuclei/cytoplasm, and pleomorphism. A tumor with none of these six factors is considered benign.

While GCT is predominantly benign, its clinical appearance can sometimes mimic malignant disease, such as skin invasion and fixation to the chest wall, making it difficult to differentiate from breast cancer by imaging [4]. By mammography (MG) it could appear as a highly dense circular/oval mass, sometimes accompanied by spiculation [5]. Calcification is rare. By ultrasonography (US), the internal echo level is usually a mixture of low and high with an irregular tumor shape. Several reports used magnetic resonance imaging (MRI) for GCT, but there are no GCT-specific imaging findings [6].

Pathological assessment of GCT is not difficult. The tumor is composed of relatively large polygonal cells with eosinophilic granules in the cytoplasm that stain positive for S-100 protein with immunohistochemistry. The standard treatment for GCT of the breast is tumor resection. The importance of negative surgical margins remains unclear, with only limited observational studies $[4,7]$. While observation periods are not consistent, no local recurrence has been reported, even in margin-positive cases.
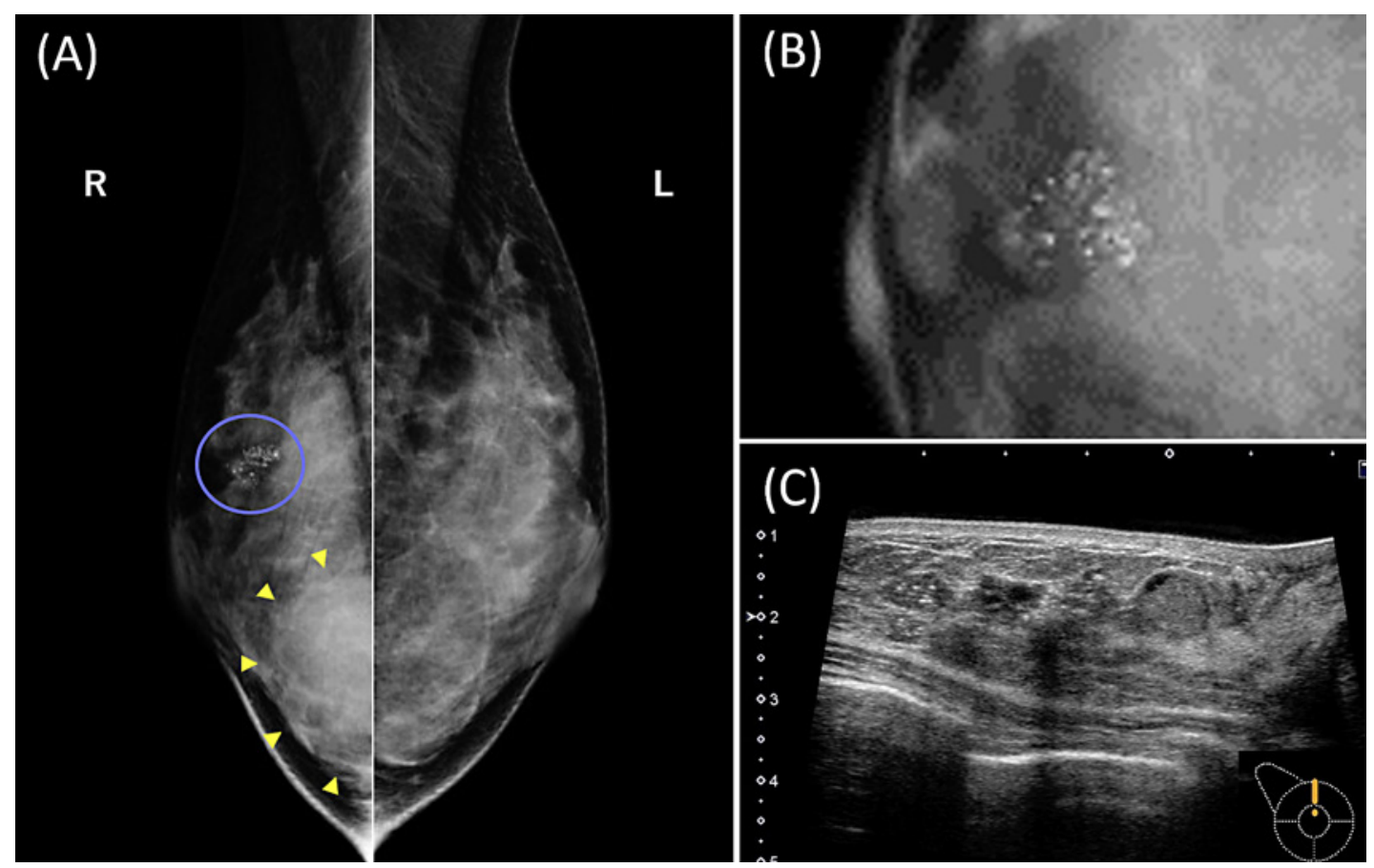

Fig. 1. MG findings and US imaging of the upper lesion in the right breast. A MG of the breast. The blue circle indicates a collection of polymorphic calcifications. The yellow arrowheads indicate a shadow of the suspected mass lesion. B Higher magnification of the collection of calcifications. C US findings of the upper lesion. MG, mammography; US, ultrasonography. 


\section{Case Reports in Oncology}

\begin{tabular}{l|l}
\hline Case Rep Oncol 2021;14:303-308 \\
\hline DOI: 10.1159/000513231 & $\begin{array}{l}\text { @ 2 2021 The Author(s). Published by S. Karger AG, Basel } \\
\text { www.karger.com/cro }\end{array}$ \\
\hline
\end{tabular}

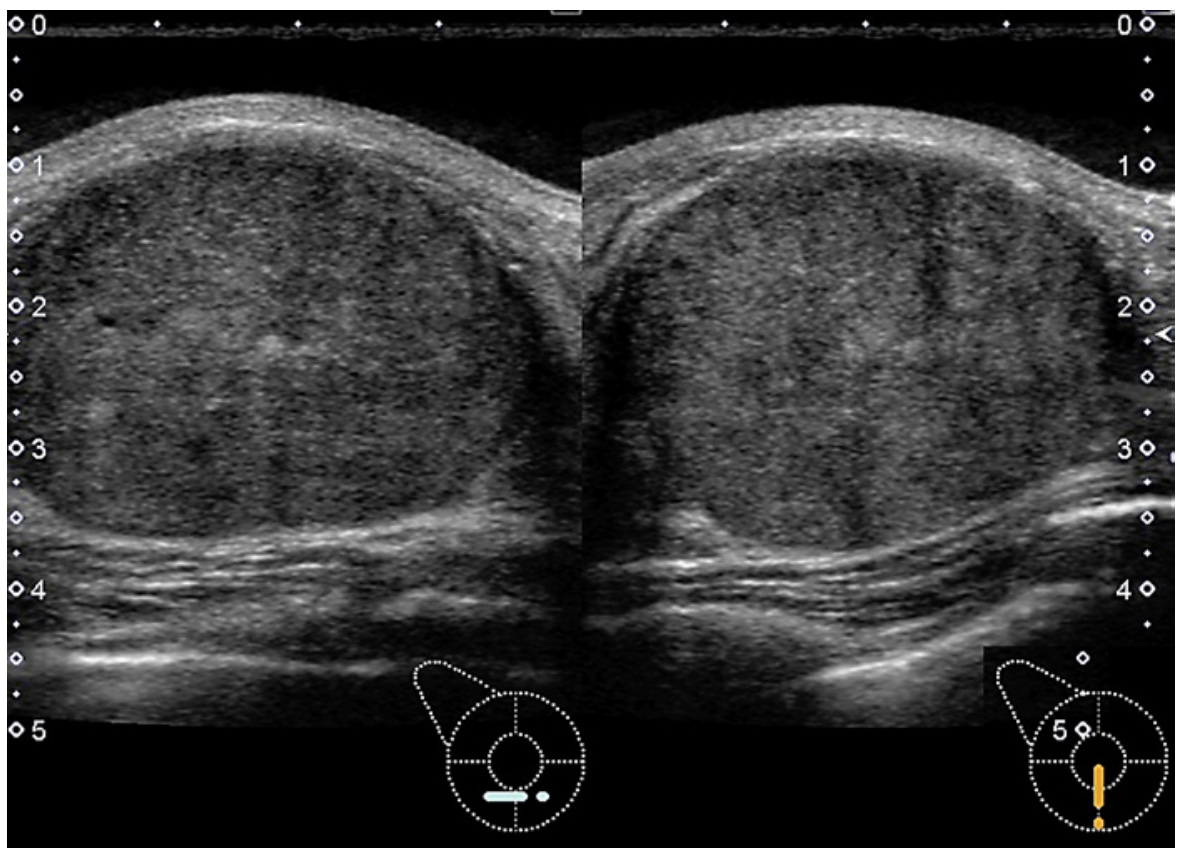

Fig. 2. US findings of the lower lesion. A circular-shaped mass with slightly uneven internal echo level was observed on US. US, ultrasonography.
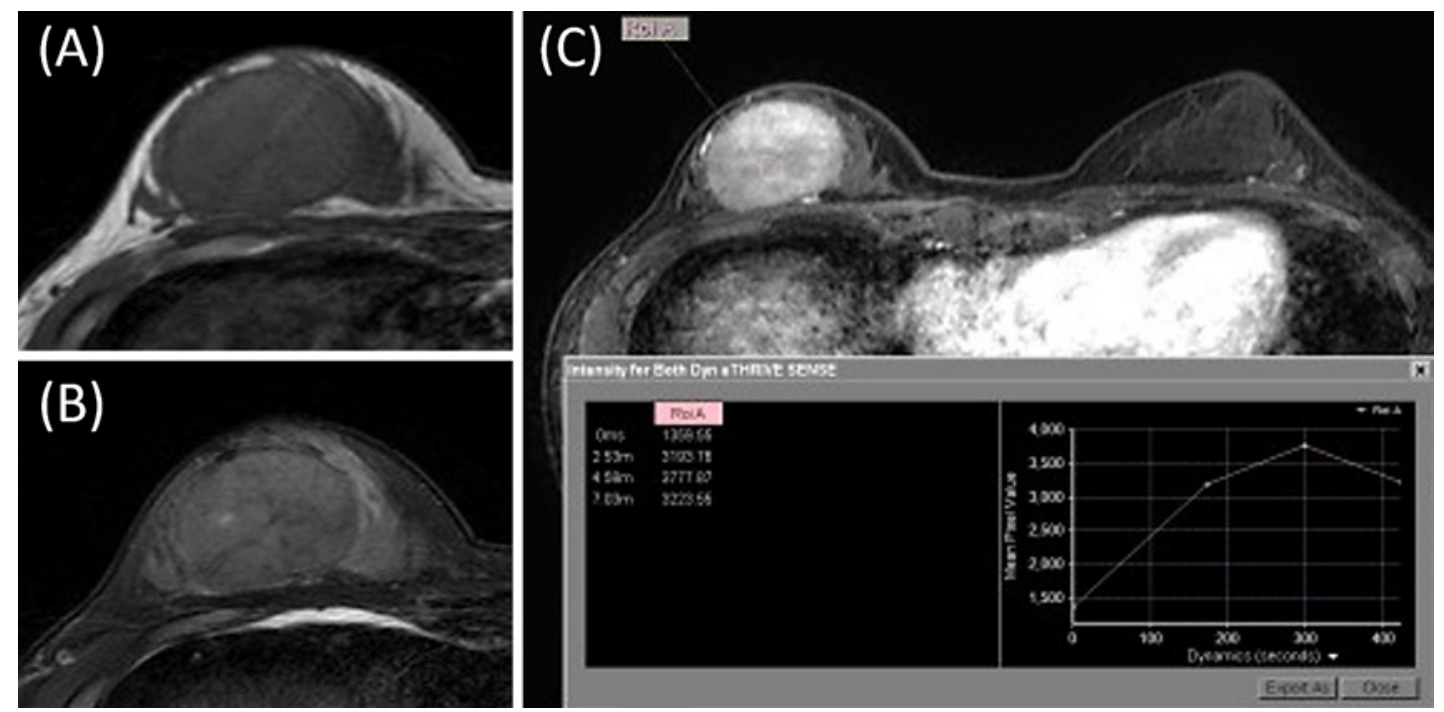

Fig. 3. MRI findings of the lower lesion. A T1-weighted image. B T2-weighted image. C Contrast-enhanced image with time-intensity curve. MRI, magnetic resonance imaging.

GCT is not generally associated with breast cancer. There are reports of GCT coexisting with breast cancer [8-11], but only one report describes a GCT colocalized with breast cancer [11]. Considering the origin cells of GCT, coexistence with breast cancer should be regarded as incidental. We herein report a rare case of GCT coexisting with a ductal carcinoma in situ (DCIS).

\section{Karger'}



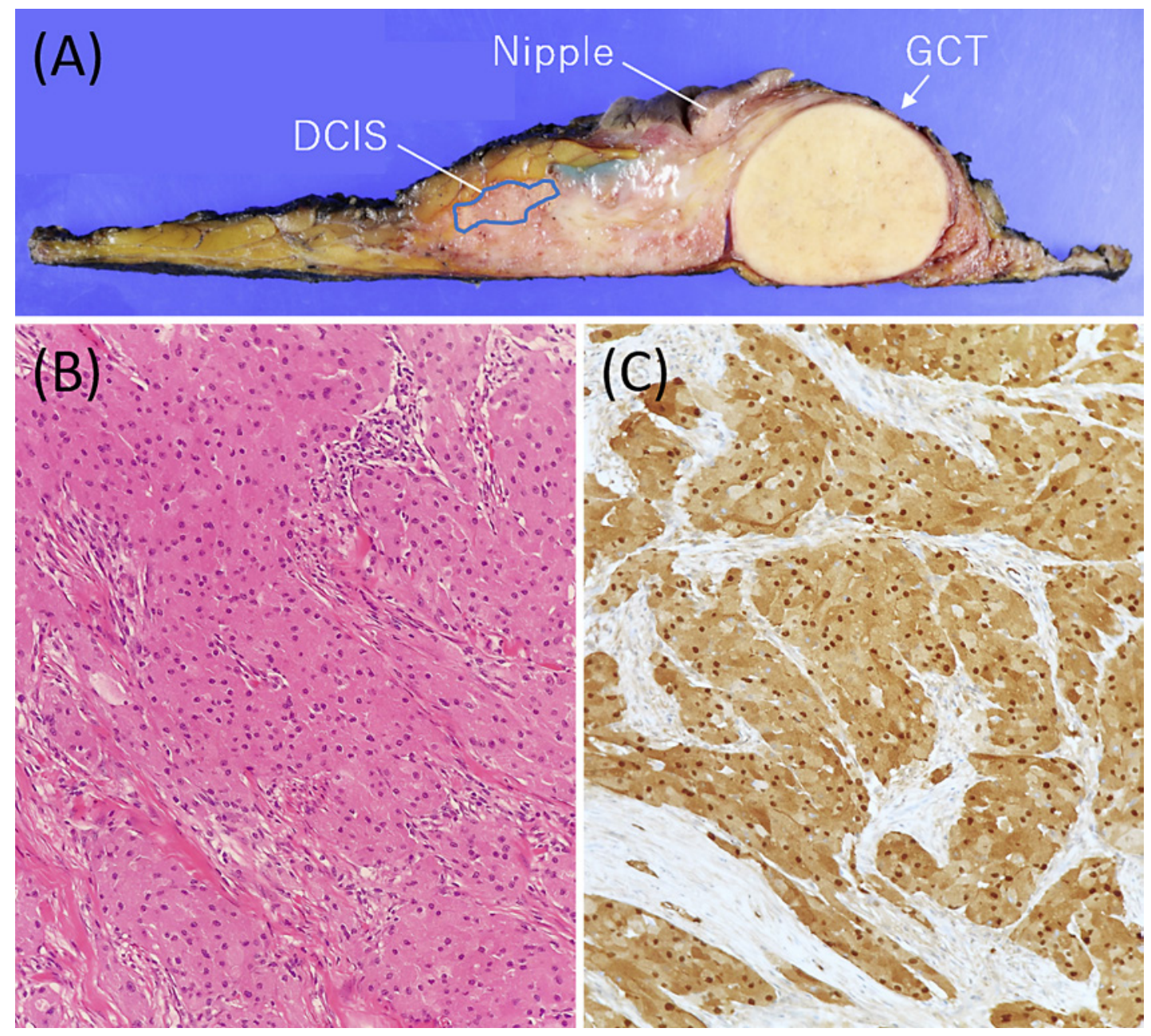

Fig. 4. Final pathological findings of GCT from the surgical specimen. A Cut surface of the surgical specimen. The blue encircling line indicates DCIS in the upper area. B Hematoxylin and eosin staining, $\times 200$. C S-100 staining, $\times 200$. DCIS, ductal carcinoma in situ; GCT, granular cell tumor.

\section{Case Presentation}

A 35-year-old Japanese woman presented at her local hospital after feeling a mass on her right breast. US found two masses of 13 and $15 \mathrm{~mm}$ in the upper and lower regions of the right breast, respectively, and both were suspected to be fibroadenoma. Three years later, she presented again and MG found microcalcification suggestive of malignancy in the upper breast. As such she was referred to our hospital. While the patient had no specific medical history, she did have a family history of breast cancer in a maternal aunt. At the first visit a 6-cm, well-defined mass was palpable in the lower breast.

MG revealed a collection of polymorphic calcifications in the upper lesion (Fig. 1A, B). US showed a hypoechoic region with an intraductal component (Fig. 1C). The patient refused a biopsy. For the lower mass, a tumor shadow was observed on MG, but compression was not sufficient and a detailed evaluation of the shape was difficult. On US, the mass was $41 \mathrm{~mm}$ in diameter, circular, with a clear border and a slightly uneven internal echo level, suggesting phyllodes tumor, fibroadenoma, or breast cancer (Fig. 2). Contrast-enhanced MRI (Fig. 3) 
found that the T1-weighted image had a slightly higher signal than the mammary gland and that the T2-weighted image had a slightly lower signal, with a clear boundary. The inside was unevenly contrast-enhanced and showed a fast/washout enhanced pattern. Malignancy could not be ruled out and a fine need biopsy diagnosed GCT.

Three months later, a follow-up US revealed that the upper hypoechoic legion had grown to $42 \mathrm{~mm}$. A US-guided vacuum-assisted biopsy diagnosed DCIS. Imaging found no evidence of continuity between the upper DCIS and the lower GCT. The patient elected to undergo mastectomy and a sentinel lymph node biopsy and tissue expander insertion were simultaneously performed.

The final pathological diagnosis of the upper lesion from the surgical specimen was grade 1 DCIS $(26 \times 9 \times 20 \mathrm{~mm})$. The lower lesion was $45 \times 40 \times 32 \mathrm{~mm}$, with the cut surface being a yellow-whitish tumor with clear boundaries (Fig. 4). Histological examination found sheetforming polygonal cells with eosinophilic granules in the cytoplasm. Tumor cells were strongly positive for S-100 and negative for keratin. The final diagnosis was GCT. Histologically there was no evidence of continuity between the DCIS and GCT.

\section{Discussion and Conclusion}

GCTs can only be diagnosed by pathology as there are no imaging-specific findings for GCT. While rare, clinicians need to be familiar with GCT and its imaging findings. A lack of awareness of this disease may lead to overdiagnosis when a GCT coexists with a breast cancer, where the GCT may be regarded as a daughter lesion. Obtaining a reliable pathological diagnosis by biopsy is crucial to ensure accurate presurgical diagnosis of the extent of breast cancer and the right choice of surgical procedure.

\section{Acknowledgments}

The authors sincerely appreciate Clear Science Pty Ltd for language editing.

\section{Statement of Ethics}

Written informed consent for publication of the present case report and any accompanying images was obtained from the patient.

\section{Conflict of Interest Statement}

The authors declare that they have no conflicts of interest to disclose.

\section{Funding Sources}

This research did not receive any specific grant from funding agencies in the public, commercial, or not-for-profit sectors. 


\section{Case Reports in Oncology}

Case Rep Oncol 2021;14:303-308

\begin{tabular}{l|l}
\hline DOI: $10.1159 / 000513231$ & (c) 2021 The Author(s). Published by S. Karger AG, Basel
\end{tabular} www.karger.com/cro

Ueki et al.: Granular Cell Tumor of the Breast Coexisting with DCIS

\section{Author Contributions}

Y. Ueki and H. Sai treated the patient and provided clinical information. Y. Horimoto and A. Arakawa conducted the histological assessment. A. Shiraishi examined and provided the imaging data. Y. Ueki and Y. Horimoto wrote the manuscript. M. Saito reviewed and edited the manuscript. All authors contributed to discussions and agreed on the final version of the submitted manuscript.

\section{References}

1 Adeniran A, Al-Ahmadie H, Mahoney MC, Robinson-Smith TM. Granular cell tumor of the breast: a series of 17 cases and review of the literature. Breast J. 2004;10(6):528-31.

2 Akahane K, Kato K, Ogiso S, Sakaguchi K, Hashimoto M, Ishikawa A, et al. Malignant granular cell tumor of the breast: case report and literature review. Breast Cancer. 2015;22(3):317-23.

3 Fanburg-Smith JC, Meis-Kindblom JM, Fante R, Kindblom LG. Malignant granular cell tumor of soft tissue: diagnostic criteria and clinicopathologic correlation. Am J Surg Pathol. 1998;22(7):779-94.

4 McCreevy CM, Peters SR, Hubbi B, Kalu ON. Radiographic imaging and clinical course of granular cell tumors of the breast. Radiol Diagn Imaging. 2019.

5 Vos LD, Tjon A, Tham RT, Vroegindeweij D, Vrints LW. Granular cell tumor of the breast: mammographic and histologic correlation. Eur J Radiol. 1994;19(1):56-9.

6 Scaranelo AM, Bukhanov K, Crystal P, Mulligan AM, O’Malley FP. Granular cell tumour of the breast: MRI findings and review of the literature. Br J Radiol. 2007;80(960):970-4.

7 Papalas JA, Wylie JD, Dash RC. Recurrence risk and margin status in granular cell tumors of the breast: a clinicopathologic study of 13 patients. Arch Pathol Lab Med. 2011;135(7):890-5.

8 Tran TA, Kallakury BV, Carter J, Wolf BC, Ross JS. Coexistence of granular cell tumor and ipsilateral infiltrating ductal carcinoma of the breast. South Med J. 1997;90(11):1149-51.

9 Mulcare R. Granular cell myoblastoma of the breast. Ann Surg. 1968;168(2):262-8.

10 Tai G, D'Costa H, Lee D, Watkins RM, Jones P. Case report: coincident granular cell tumour of the breast with invasive ductal carcinoma. Br J Radiol. 1995;68(813):1034-6.

11 Al-Ahmadie H, Hasselgren PO, Yassin R, Mutema G. Colocalized granular cell tumor and infiltrating ductal carcinoma of the breast. Arch Pathol Lab Med. 2002;126(6):731-3. 